\title{
Traumatic Atlanto-Axial Rotary Subluxation (AARS) in a 6-Year- Old Child during Recreational Jūdō Practice: A Case Report and Mini-Review of Serious Neck Injuries in Jūdō
}

\author{
Carl De Crée $e^{1,2^{*}}$ \\ ${ }^{1}$ Laboratory for Exercise Physiology and Endocrinology, Sports Medicine Research Laboratory, Malines, Belgium \\ ${ }^{2}$ Division of South and East Asia: Japan Studies, Department of Languages and Cultures, Ghent University, Belgium
}

\begin{abstract}
Case presentation: A 6-year-old Caucasian girl with approximately 1 year of recreational jūdō experience presented with neck and shoulder pain while holding her head in a "Cock-robin" sideways tilted position. During a children's jūdō class while seated on "all fours" she had been subjected to an improperly executed turnover performed by a boy of similar age, body mass and experience. Because of increasing torticollis symptoms after class she was taken by her parents to a local hospital's emergency department where X-rays showed a mid-clavicular fracture. It was not until 7 weeks post-accident that a CT scan was ordered and a type-III traumatic acute AARS causing her clinical symptoms was recognized.
\end{abstract}

Differential diagnosis: Congenital cervical spine anomalies, Grisel's syndrome, Juvenile rheumatoid arthritis, Odontoid fracture without atlanto-axial dislocation.

Treatment: A halo crown traction brace connected to a cervical traction pulley with gradual increased weight $(+0.5 \mathrm{~kg}$ every half day to a maximum of $6.5 \mathrm{~kg}$ ) was used for reduction over a 17-day period, followed by 6 weeks of ambulant immobilization with a halo vest, and 8 weeks of wearing a stiff neck brace. The girl fully recovered but was advised not to return to practicing contact sports until achieving skeletal maturity.

Uniqueness of the study: AARS has not previously been described in association with jūdō practice in children.

Conclusion: Traumatic AARS should be considered as a potential diagnosis in jūdōka, especially those of very young age and of female gender, when presenting with torticollis following mechanical impact or severe pressure on the head if blocked in a tilted position. Prompt diagnosis is crucial, preferably by open-mouth X-rays and CT scan, to ensure proper management and prevent neurological complications.

\section{Keywords}

Athletic injuries, Atlanto-axial, Cervical vertebrae, Children, Judo, Martial arts, Neck injuries, Sports injuries, Sprains and strains

\section{Introduction}

It has been suggested that several fatalities due severe head and neck injuries have occurred in jūdō [1-3]. While the majority of fatal accidents were due to closed head trauma that involved subdural or epidural bleeding and subsequent cerebral compression [1-8], jūdō neck injuries have not been properly investigated $[9,10]$. Scarce studies, such as the one by Green, et al. [11], found that neck injuries associated with participation in jūdō contests occurred at a rate of 1.03 per 1000 Athlete Exposures, with one Athlete Exposure representing the susceptibility to injury, expressed as one athlete participating in one match or practice session in which he or she is exposed to the possibility or injury. Despite the rarity of head and especially neck injuries sustained during jūdō practice this has not prevented some authors from having made recommendations that even have included abolishing several supposedly too dangerous jūdō techniques $[5,6]$.

*Corresponding author: Professor Carl De Crée, Laboratory for Exercise Physiology and Endocrinology, Sports Medicine Research Laboratory, B-2800 Malines, Belgium, Fax: +44-870762-1701

Accepted: April 02, 2019

Published online: April 04, 2019

Citation: De Crée C (2019) Traumatic Atlanto-Axial Rotary Subluxation (AARS) in a 6-Year-Old Child during Recreational Jūdō Practice: A Case Report and Mini-Review of Serious Neck Injuries in Jūdō. Arch Sports Med 3(1):134-148 
Citation: De Crée C (2019) Traumatic Atlanto-Axial Rotary Subluxation (AARS) in a 6-Year-Old Child during Recreational Jūdō Practice: A Case Report and Mini-Review of Serious Neck Injuries in Jūdō. Arch Sports Med 3(1):134-148

Of particular interest among cervical neck injuries in jūdō are traumatic atlanto-axial rotational subluxations (AARS). The term refers to a rotational subluxation or dislocation of $\mathrm{C} 1$ on $\mathrm{C} 2$ and represents a serious condition that is associated with neurological complications such as cervical myelopathy, vertebro-basilar insufficiency symptoms and may lead to paralysis or sudden death due to spinal cord and brain stem compression [12-14]. In addition, AARS are sometimes misdiagnosed hence increasing the risk for such complications [15-18].

Expanding the number of more commonly known cervical spinal problems associated with jūdō practice, the present paper introduces and discusses a recent case of a juvenile jūdōka presenting with torticollis and traumatic AARS. Currently, to the best of our knowledge, no literature data on the prevalence of this specific injury in jūdo, especially in children, are available.

\section{Case Presentation}

A 6-year-old Caucasian girl presented with neck and shoulder pain while holding her head in a sideways tilted position. The subject had approximately 1 year of jūdō experience and held the rank of gokyū (fifth class yellow belt). She had never competed in any jūdō contests and was only recreationally active in a group of approximately 30 kids between the ages of 5-6 years. There were neither anorexic, nor any obese children within her training group. During jūdō practice at her local club while she was seated in yotsunbai [position "on all fours"] i.e. on hands and knees during newaza [mat work], a nogare-kata [turnover exercise] (Figure 1) was performed on her by her practice partner - a boy of similar age and body mass - which caused her to feel a sudden discomfort in her neck and shoulder area. The instructor in charge did not notice any unusual signs of distress in the girl that would have prompted him to interrupt class and call for medical assistance. Hence the girl remained sitting down along until the class finished twenty minutes later, at which point she was driven home by her mother.

Over the next two hours though, the girl suffered from persistent worsening neck pain. She was no longer able to move her left arm and showed dystonic contractions of the neck, i.e. left lateral torticollis with sternocleidomastoid spasticity ("Cock-Robin" position). In consequence, her parents sought medical attention at a local hospital's emergency room. Radiographic evidence and clinical evaluation led the attending physician to conclude that the girl had a clear left midclavicular fracture. However, she was sent home without either a figure-of-eight bandage or simple sling applied.

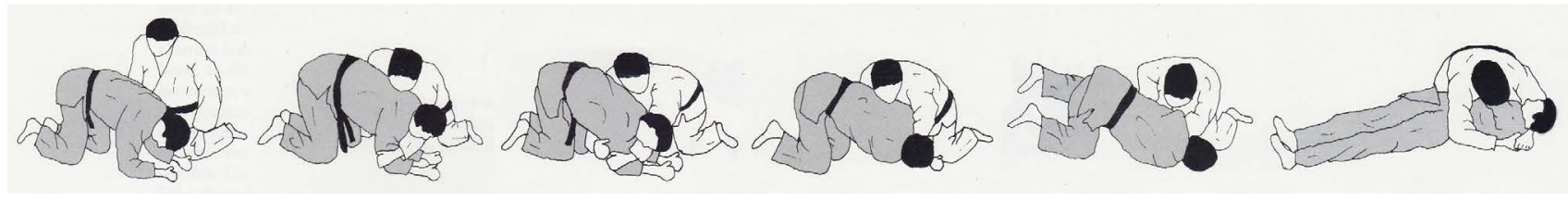

Figure 1: Nogare-kata [turnover exercise] performed on a practice partner seated in yotsunbai [position "on all fours"] i.e. on hands and knees during newaza [mat work] (modified after [19], copyright @ , R. van Alff. All rights reserved).



Figure 2: Axial CT-scan images showed an acute atlanto-axial rotational subluxation of C1 on C2 or "AARS". An increased anterior/ posterior deviation and widening of the atlanto-dental distance to approximately $11 \mathrm{~mm}$ with slight inferior displacement of the articular surfaces of the left side of the atlas with reference to the axis, i.e. Ishii Grade II $\left(<20^{\circ}\right)$ [20] can be seen on the sagital image. The right atlanto-axial joint is subluxated towards posterior over an approximately $8 \mathrm{~mm}$ distance. The atlas with reference to the axis is rotated towards the left and displaced towards inferior, and dislocated towards anterior. No fractures were observed. Hence, the diagnosis was made of a Fielding and Hawkins Type-III [21] traumatic acute atlanto-axial rotational subluxation of C1 on C2 or "AARS. 
Because of their continuing worries - the girl was unable to lie down in bed and had to spend the night, as well as the night after seated in a chair while her discomfort seemed to be worsening rather than improving - the girl's parents two days later took her to a different hospital for a second opinion where she was seen by an orthopedic physician, who this time applied a figure-of-eight bandage to support her fractured clavicle. Follow-up X-rays taken two weeks later showed a positively evolving healing process of the clavicular fracture. However, the girl was still unable to attend school or to sleep while lying flat in a bed at night hence the physician also prescribed 18 physical therapy sessions for her laterocollis of the neck.

Although the torticollis improved somewhat, during a further check-up four weeks later the girl's head was still positioned in an abnormal left lateraloflexion. At that point a second medical opinion was sought.

\section{Investigations}

At the time the patient sought a second opinion, i.e. with a "seven and-a-half-week delay since the accident had occurred, torticollis with the head in abnormal left lateraloflexion was confirmed. Therefore, a soft neck collar and MRI were prescribed. However, based on the MRI findings a computed tomography (CT) scan was ordered. Axial CT-scan images showed an acute atlanto-axial rotational subluxation of $\mathrm{C} 1$ on C2 or "AARS". An increased anterior/posterior deviation and widening of the atlanto-dental distance to approximately 11 $\mathrm{mm}$ with slight inferior displacement of the articular surfaces of the left side of the atlas with reference to the axis, i.e. Ishii Grade II $\left(<20^{\circ}\right)$ [20] can be seen on the sagital image (Figure 2). The right atlanto-axial joint is subluxated towards posterior over an approximately $8 \mathrm{~mm}$ distance. The atlas with reference to the axis is rotated towards the left and displaced towards inferior, and dislocated towards anterior. No fractures were observed. Hence, the diagnosis was made of a Fielding and Hawkins Type-III traumatic acute atlantoaxial rotational subluxation of C1 on C2 or "AARS [21]. It is pointed out that diagnosis was made with a seven-and-a-halfweek delay since the accident had occurred.

\section{Differential diagnosis}

- Atlantoaxial fixation;

- Congenital cervical spine anomalies, such as Goldenhar syndrome (skeletal dysplasia with hypoplasia of the dens and atlanto-axial instability), Klippel-Feil syndrome (cervical vertebral fusion syndrome), Morquio syndrome (skeletal and odontoid dysplasia as a consequence of mucopolysaccharidosis type-IV), or osseous abnormalities (occipitalization of the atlas);

- Grisel's syndrome (torticollis involving nontraumatic atlanto-axial subluxation due to inflammatory ligamentous laxity secondary to retropharyngeal infection, though rare, mostly occurring in children);

- Juvenile rheumatoid arthritis;

- Odontoid fracture without atlanto-axial dislocation.

\section{Treatment}

Management included analgesia and sedation, with the patient being prescribed oral midazolam (Dormicum ${ }^{\circledR}$ ) $10 \mathrm{mg}$ and transdermal alfentanil (Rapifen ${ }^{\circledR}$ ) $12 \mu \mathrm{g} / \mathrm{h}$ release. After consultation with a neurosurgeon and a pediatric orthopedic surgeon it was decided to perform closed reduction by means of a constant force halo crown traction brace affixed with screws to the outer portion of the patient's skull while lying in supine position. The halo crown traction brace was then connected to a cervical traction pulley with gradual increased

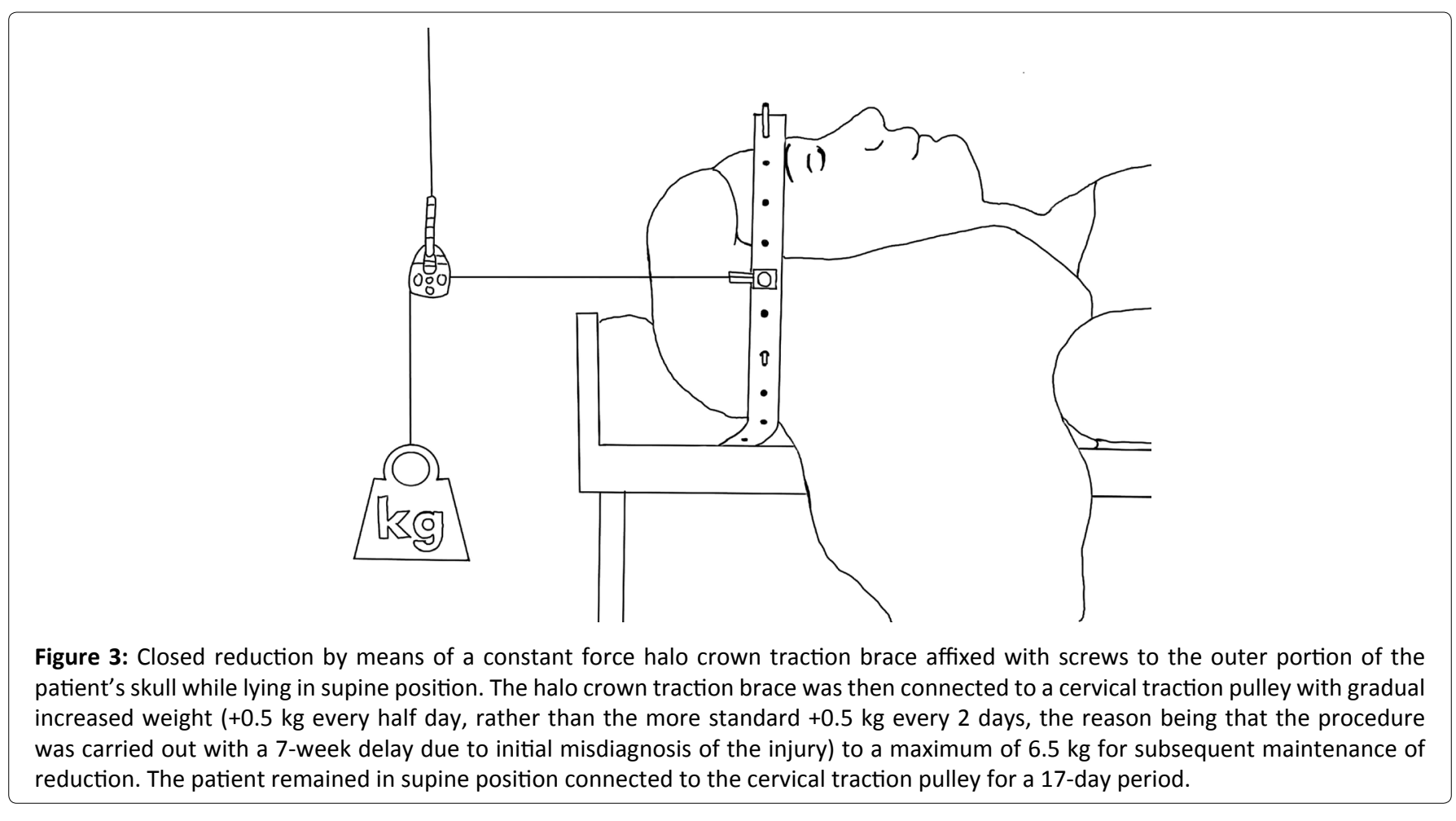




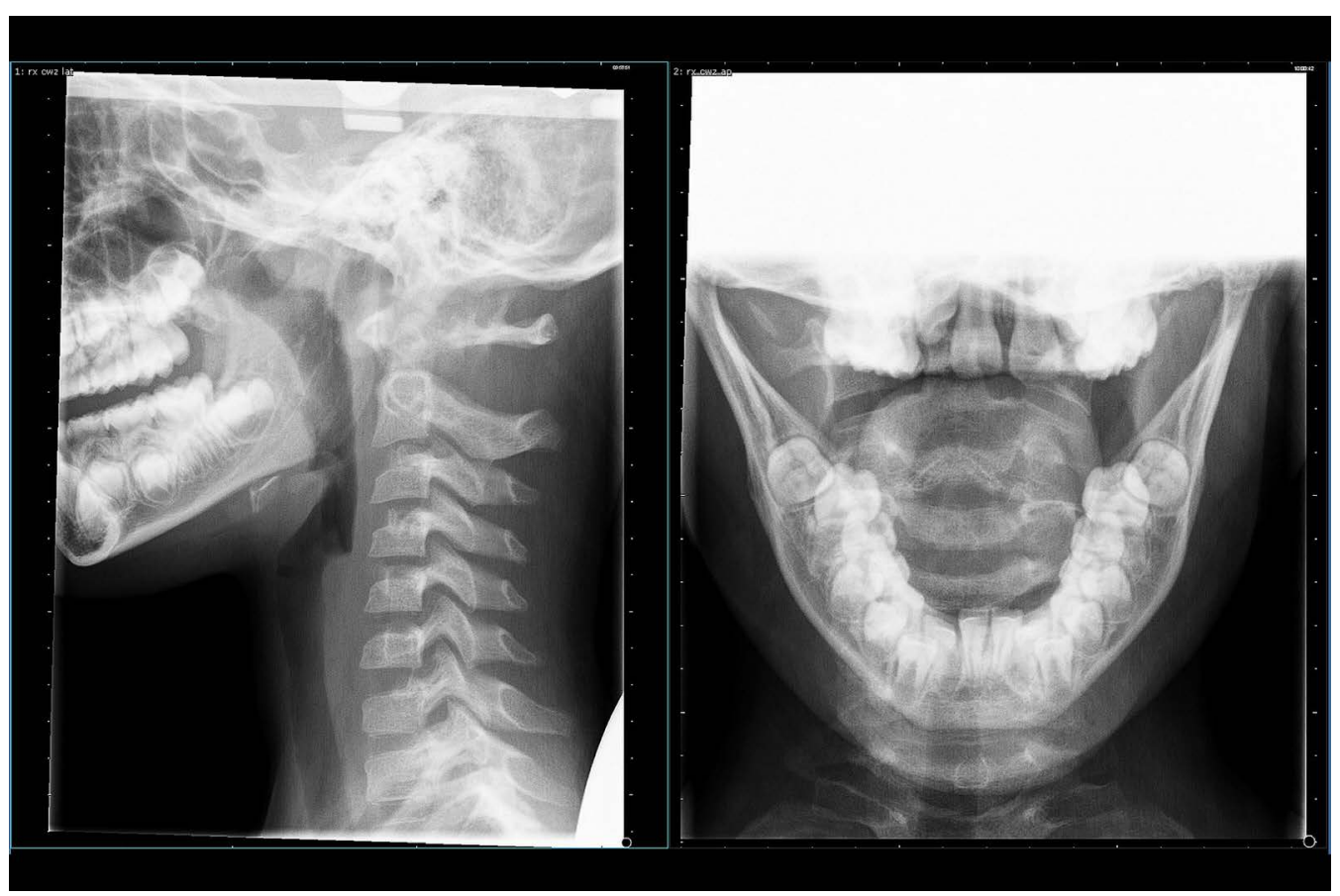

Figure 4: One week after surgical procedure X-rays still showed a slightly rotated projection of the dens as opposed to the left and right massa lateralis, with a slightly asymmetric interfacetal joint gap. Lateral view showed a normal atlanto-dental distance, but still an enlarged distance between the posterior arcs of $\mathrm{C} 1$ and $\mathrm{C} 2$.

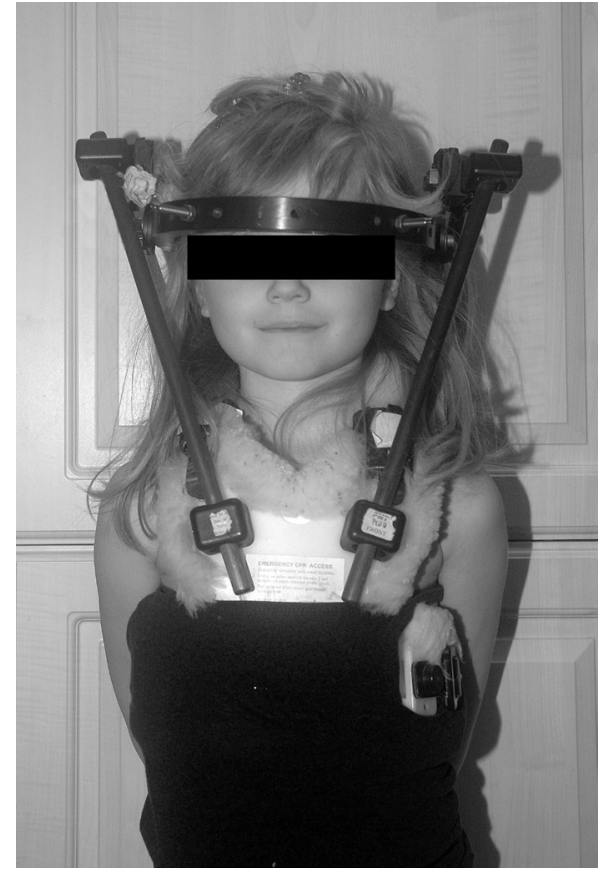

Figure 5: The child was further managed with a halo crown vest for ambulant immobilization for 6 more weeks. The Halo vest skeletal fixator device consists of a halo vest with a sheepskin and synthetic jacket underneath, support rods, a ring affixed to the outer portion of the patient's skull with pins. The system is made from carbon fiber and therefore MRI-compatible. To achieve the desired force, each skull pin is tightened individually.

weight ( $+0.5 \mathrm{~kg}$ every half day, rather than the more standard $+0.5 \mathrm{~kg}$ every 2 days, the reason being that the procedure

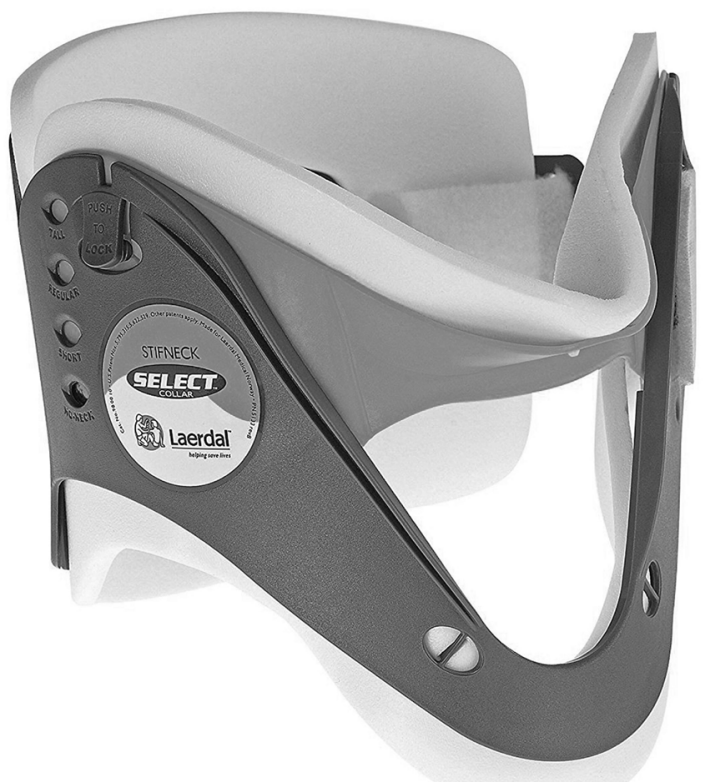

Figure 6: Example of a rigid cervical neck brace.

was carried out with a 7-week delay due to initially failing to recognized and correctly diagnose the injury, and it was felt that reduction needed to occur as soon as possible to avoid having to resort to cervical fusion as an alternative) to a maximum of $6.5 \mathrm{~kg}$ for subsequent maintenance of reduction. The patient remained in supine position connected to the cervical traction pulley for a 3-week period (Figure 3). $X$-Rays were taken at one-week intervals to monitor clinical progress. One week after the procedure X-rays still showed a slightly rotated projection of the dens as opposed to the left 
and right massa lateralis atlantis, with a slightly asymmetric interfacetal joint gap. Lateral view showed a normal atlantodental distance, but still an enlarged distance between the posterior arcs of C1 and C2 (Figure 4).

The child was released from hospital sooner than planned, i.e., 17 days post-intervention. To ensure ambulant immobilization for 6 more weeks, the halo ring was attached to a halo vest. The halo vest skeletal fixator device consists of a halo vest with a sheepskin and synthetic jacket underneath, support rods, a ring and skull pins. The system is made from carbon fiber and therefore MRI-compatible. To achieve the desired force, each skull pin is tightened individually (Figure 5). No further medication was prescribed. When those 6 weeks had elapsed and following radiological confirmation that the objective had been achieved and the halo device been removed, the patient was instructed to wear a stiff neck collar for another 8-week period (Figure 6). Afterwards, she was allowed to switch to an adjustable neck support \& brace foam cervical collar wrap, which she wore for another 2 months. No additional physical therapy was prescribed.

\section{Outcome and follow-up}

Follow-up 12 months after the accident had occurred, the child had completely normalized daily activities, had no neurological or motor deficiencies, or discomfort. The girl fully recovered but was not allowed to return to practicing contact sports, with jūdō being advised as contraindicated until at least after completing puberty, or even until skeletal maturity is achieved.

\section{Discussion}

\section{Diagnosis}

The atlantoaxial joint is the most mobile portion of the spine, predominantly relying on the ligamentous framework for stability at that level [22]. The joint is subject to a number of injuries including: Atlanto-occipital dissociation, occipital condyle fractures, atlas fractures with transverse ligament rupture, atlanto-axial distraction, and traumatic rotatory subluxation [23], though many of these injuries are rare especially in situations where no motor vehicles were involved $[13,14]$.

Some cases of AARS are accompanied by a more obviously present clavicular fracture [24] which may cause the examining physician to ignore and miss the AARS diagnosis. However, the most typical symptoms when AARS is suspected are pain and torticollis. The pain may vary from mild discomfort to great agony, while the torticollis is characterized by a head position tilted to one side and rotated to the other with slight flexion ("Cock-robin" position). Muscle spasms may aggravate the forward subluxation of C1 on C2 [25]. Approximately 50\% of the rotational radius of action of the cervical spine takes place at C1-C2 [26]. In case of traumatic injury transverse ligament integrity is relevant, with an atlanto-dens interval (ADI) of $>5 \mathrm{~mm}$ indicating an incompetent ligament and denoting instability. Because of the potential risk for spinal canal stenosis prompt diagnosis is crucial. In fact, it is possible for spinal canal stenosis to occur secondary to severe rotation even in the presence of a competent transverse ligament. However, because the spinal canal of C1 is relatively large, it can safely accommodate rotation and some degree of pathologic displacement without compromising the spinal cord. For this reason, fortunately AARS following minor trauma in patients without additional predisposing conditions, is rarely associated with neurologic deficit [25].

In the present case proper diagnosis was missed repetitively, and this by several physicians, until more than 7 weeks after the trauma, and this despite having taken $\mathrm{X}$-rays. Delayed diagnosis in these challenging cases due to time pressure and busy shifts at hospital emergency departments has been known to occur and is reported in the literature $[12,17]$. Yet, delayed diagnosis in this case may lead to worsening neurological problems and complicate management [12]. Most authors feel that the first six weeks after the accident are crucial for closed reduction treatment of this particular type of injury to be successful, because the outcomes of treatment are affected by the duration of symptoms [12]. If posing a proper diagnosis keeps getting missed for a long period of time cervical fusion may be the only solution left $[13,15,27]$.

X-Rays are the obvious choice for initial assessment of cervical trauma in children, and should include anteroposterior, lateral, and open-mouth odontoid views in a neutral position [28-30]. During antero-posterior and openmouth views one may often observe an asymmetric distance between the dens and the lateral mass, accompanied by a lateral mass displaced towards anterior and appearing wider and closer to the midline. Lateral view X-rays will typically show a lateral facet that has moved towards anterior and that rather than oval-shaped will appear wedged. Using cervical extension-flexion views to attempt estimating the atlantodens interval and any eventual cervical instability is usually not a very good idea due to the presence of sternocleidomastoid spasms, torticollis, pain and overall discomfort during the acute phase.

Many physicians will follow up with magnetic resonance imaging (MRI) when either the X-rays are indicative of a potentially serious problem or not corresponding with the patient's complaints. MRI is especially useful during the first 48 hours in those patients where neurologic status cannot otherwise be properly identified, as it will provide soft tissue detail allowing evaluation of ligaments including any eventual disruption of the transverse atlantal ligament, spinal soft tissue and associated spinal cord compression injuries [23]. It is also an important tool in making the differential diagnosis, such as ruling out any soft-tissue or bone infections that might cause torticollis.

It is, however, thin-section multidetector computed tomography (CT) with sagital and coronal reformats that is recommended and that remains the gold standard to evaluate the extent of the injury and to maximally enhance specificity $[23,28,30]$. Hence, any atlanto-axial subluxation will be clearly visible on the CT scan. Additionally, it can evaluate and provide the best possible estimation of any eventual lateral inclination and inferior displacement of $\mathrm{C} 1$, and the stability of the spine. 


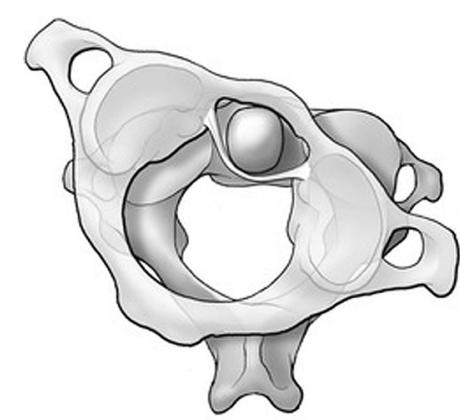

Type I

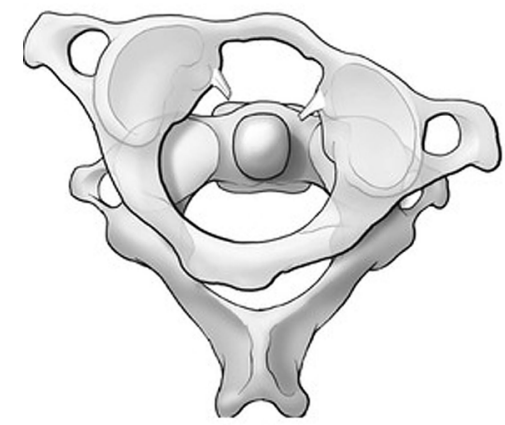

Type III

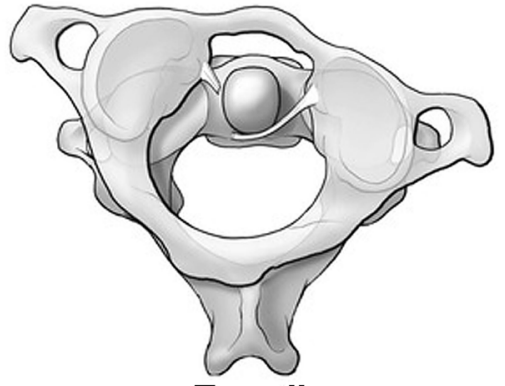

Type II



Type IV

Figure 7: The Fielding and Hawkins classification [21] is one of the most used classification systems that can help in the interpretation of the radiological investigations. AARS cases can be subdivided according to the degree of displacement into 4 types.

The Fielding and Hawkins classification is one of the most used classification systems [31] that can help in the interpretation of the radiological investigations (Figure 7). AARS cases can be subdivided according to the degree of displacement into:

- Type I: Simple rotational displacement, or more specifically, a unilateral facet subluxation with intact transverse ligament, with the dens acting as the pivot. This is the most commonly occurring one of all 4 types.

- Type II: Unilateral facet subluxation with an anteroposterior displacement or atlanto-dens interval (ADI) of 3-5 $\mathrm{mm}$. This type is associated with transverse ligament injury, where the facet is now acting as pivot.

- Type III: Bilateral anterior facet or anterior-posterior displacement more than $5 \mathrm{~mm}$. This type contains a risk of neurologic deficit, but is rare.

- Type IV: Posterior displacement of the atlas, accompanied with dens deficiency. This type is also rare and has a high risk of neurologic deficit.

The extent of the latero-inferior inclination angle of C1 can be classified according to Ishii [20] as follows:

- $\quad$ Grade I: $0^{\circ}$;

- Grade II: $<20^{\circ}$, accompanied by facet deformity;

- Grade III: $>20^{\circ}$, accompanied by facet deformity.

\section{Injury mechanism}

If the head gets stuck with the neck relatively immobile position while remaining under traction in either hyperflexion or hyperextension, then any rotational movement of the body in reference to the head will cause a torsion of the spine. The combined hyperextension or hyperflexion of the neck with torsion not only significantly reduces the stability of the vertebral bodies, but is likely to subluxate, dislocate or fracture vertebral bodies causing maximal biomechanical instability and ligamentous ruptures [32-35].

In their study, Kamitami, et al. [6], found that $58 \%$ of a variety of neck injuries associated with jūdō practice were seen in teenagers the majority of injuries occurring while executing offensive maneuvers. In the case of AARS, the injury occurs as a rotational shear injury that causes ligamentous instability at C1 on C2 and leads to an anterior displacement of the dens [12]. Even a trauma as mild as a head-over-heels may result in atlanto-axial [25]. In jūdō, situations of abnormal muscular stress or mechanical torque can be caused by virtually every movement in nage-waza (throwing techniques) or newaza (groundwork).

When such severe head or neck injuries do involve elite athletes, they are typically well-documented and discussed in the media and accompanied by video footage, pictures, and sometimes by follow-up X-rays or MRI-scans. One can find back very few such cervical injuries $[2,8,10,36]$. A notorious case was the cervical dislocation and neck fracture of double world champion Gella Vandecaveye (-61 kg, later $-63 \mathrm{~kg}$ ) from Belgium during the 1998 European women's team championships in Villach, Austria. The scenario included a failed attempt to perform harai-goshi [sweeping hip throw] with insufficient unbalancing, rotation and control that resulted in falling forward slamming her head into the mat with the opponent initially blocking off the throw, and then ending on Vandecaveye's back hence increasing the force of the impact [37]. The actual cervical dislocation and fracture 




Figure 8: Former double world champion Gella Vandecaveye $(-61 \mathrm{~kg}$, later $-63 \mathrm{~kg})$ from Belgium during the 1998 European women's team championships in Villach, Austria in a failed attempt to perform harai-goshi [sweeping hip throw], that is being blocked off by her opponent's left arm and left leg. Instead of applying action/reaction and the principle of giving way, Vandecaveye decided to proceed against the force despite her lack of unbalancing her opponent, poor control with her back-twisted right arm, and insufficient rotation to the left, hence her movement unavoidably resulting in falling forward slamming her head into the mat. Her opponent initially blocking off the failed throw then ends up on Vandecaveye's back increasing the force of the impact. The actual cervical fracture in this case likely did not come from the impact of hitting the tatami, but was caused by the opponent attempting to control Vandecaveye to initiate newaza [groundwork], by jumping on top of Vandecaveye with both her body mass and force, and pressing on Vandecaveye while the latter's head was trapped between the tatami and her left shoulder, rotated to the left and with her neck in hyperextension. We note that despite Vandecaveye's obvious serious cervical spinal injury she was also turned over from a prone into a supine position by medical staff without anyone at all supporting her head and neck, which could have further aggravated her injury and have caused paralysis.

in this case likely did not come from the impact of hitting the tatami, but was caused by the opponent attempting to control Vandecaveye for the purpose of initiating newaza [groundwork] by jumping on top of her using her body mass and force, while Vandecaveye's head was trapped between the tatami and her left shoulder, her head rotated to the left with the neck in hyperextension (Figure 8).

Coincidentally, the only case of a cervical dislocation described in Catanese's book on jūdō injuries involved the exact same mechanism, throw and circumstances, and was recorded in the New York area involving an experienced, though not elite, male jūdō athlete who had insisted on participating in a tournament after having been out of the sport for several years [36]. Although Vandecaveye, thanks to immediate expert handling of her injury was able merely 5 months later to win another world title, the jūdōka in New York remained paralyzed for life.

Kamitami, et al. [6] in their study reported 11 jūdō athletes with fracture-dislocations of the cervical vertebrae, the majority (9 of them) involving C4 and C5. Uchi-mata [inner thigh throw] was the throw most frequently ( 7 times) involved in these injuries with each time the injured athlete being the one attempting the throw. In other words, the mechanism is nearly identical to what we described above in the two cases involving harai-goshi [sweeping hip throw], i.e.: not succeeding in throwing the opponent and failing to properly exert control and not or insufficiently rotate, and consequently crashing with the forehead or top of the head into the tatami while the neck is in hyperflexion or-extension, with the opponent meanwhile using his or her body mass and force pressing down on the thrower in an attempt to take control of him or her on the ground. Uchi-mata, or better, improperly performed uchi-mata, was also the culprit that caused a unilateral $\mathrm{C} 5-\mathrm{C} 6$ facet fracture dislocation in the jūdōka attempting the throw, as described by Uzel, et al. [38].

Particularly grave were the consequences of the accident sustained in October 2006 by Senegalese double African Continental Champion -63 kg, Fanta Keita, in Rabat, Morocco, who was caught off-guard by someone unexpectedly throwing her on the head prior to the start of the training session hence causing her to dislocate her cervical spine at C4-C5 [39]. The athlete succumbed following surgery. So, this accident had nothing to do with any jūdō throwing technique being potentially dangerous, but with a behavioral offense that violated safety protocols and normal behavioral rules of jūdō.

The International Judo Federation's (IJF) Refereeing Rules already prohibit "head-diving", i.e. a situation where the throwing athlete dives, head first, towards the mat in an extreme attempt to score by causing his opponent to lose balance and fall. However, what is known as "head diving" in jūdō is not entirely identical with the mechanism of injury in these cervical spinal subluxations, dislocations or fractures, unlike what is often suggested. Firstly, though "head diving" admittedly represents an incorrect application of a jūdō throwing techniques (usually of uchi-mata or harai-goshi), it is still a relatively controlled attempt, since the thrower at one moment after initiation of the technique decides to apply "head diving" and continue this movement; secondly, in a completed "head dive" technique the thrower typically completes a head-over-heels movement while still holding on to the opponent and pulling him or her with in the movement. Whilst in small children head-over-heels movements have been known to cause cervical subluxations and dislocations [25], this is unlikely to occur in a fit and healthy adult. During such "head diving" movements the thrower usually hits the 
tatami with the back of the head and neck. However, during the accidents described above, the thrower typically had no intent to do a "head dive" or complete the throw with a head-over-heels movement. Instead the injuries resulted from standard forward jū largely lacked control hence sending the thrower with the forehead or top of the head slamming into the tatami, while the opponent uses his/her body mass and force intending to control the thrower on the ground while completely disregarding the precarious anatomical position of the thrower's head trapped in a hyperflexed or hyperextended positions (often accompanied by at least a partial rotation of the head) between his/her shoulder and the mat.

In other words, while "head diving" and the mechanism of some of the cervical neck injuries may show some superficial similarities, they are in fact different. In consequence, and contrary to what may be generally assumed, the IJF's prohibition on "head diving" is very unlikely to stop or even contribute much towards limiting such serious cervical neck injuries.

Although it is not entirely clear if any of the abovementioned cervical injuries represented antlanto-axial subluxations or dislocations, the circumstances during which such injuries could occur are identical. These are real accidents, and as the video recording of Vandecaveye shows, they usually cannot be related to the throwing technique involved being specifically dangerous. Instead the accidents described above each of them involving jūdō throws, are a combination of circumstances, with the technique being a poor attempt or otherwise completely failing, or the action rather than including a pure jūdō technique representing a so-called "chaotic technique"; chaotic techniques are techniques that cannot really be identified as a true or proper jūdō throw, but are an ongoing combination of push/pull offense and defense actions and reactions and ultimately losing balance and control that eventually result in one or both jūdōka ending up on the tatami in an aberrant position without making or being able to perform standard ukemi or break falls (Figure 9). Such "chaotic techniques" lacking much of the substance of a well-executed jūdō technique will continue to be prevalent in competitive jūdō. After all nothing in the IJF refereeing rules requires that in order to score a 'throw' has to largely meet the profile of a certain identifiable jūdō throw, but only that the person thrown should "largely fall on the back, with considerable force and speed" in order to score ippon [full point] [IJF Refereeing Rules art. 20] ...

All of the above cases differ from the case study we present in terms of having occurred during tachi-waza or standing jūdō. The AARS incurred by the 6-year-old girl, presented by us, occurred during newaza or groundwork. While she was seated in yotsunbai [position "on all fours"], i.e. on hands and knees during newaza [mat work], her practice partner incorrectly attempted to perform nogare-kata, turning her over on her back. A whole range of such exercises exist within the jū $\bar{o}$ curriculum, but typically, only a few of the most straightforward and easy ones are taught to small children with

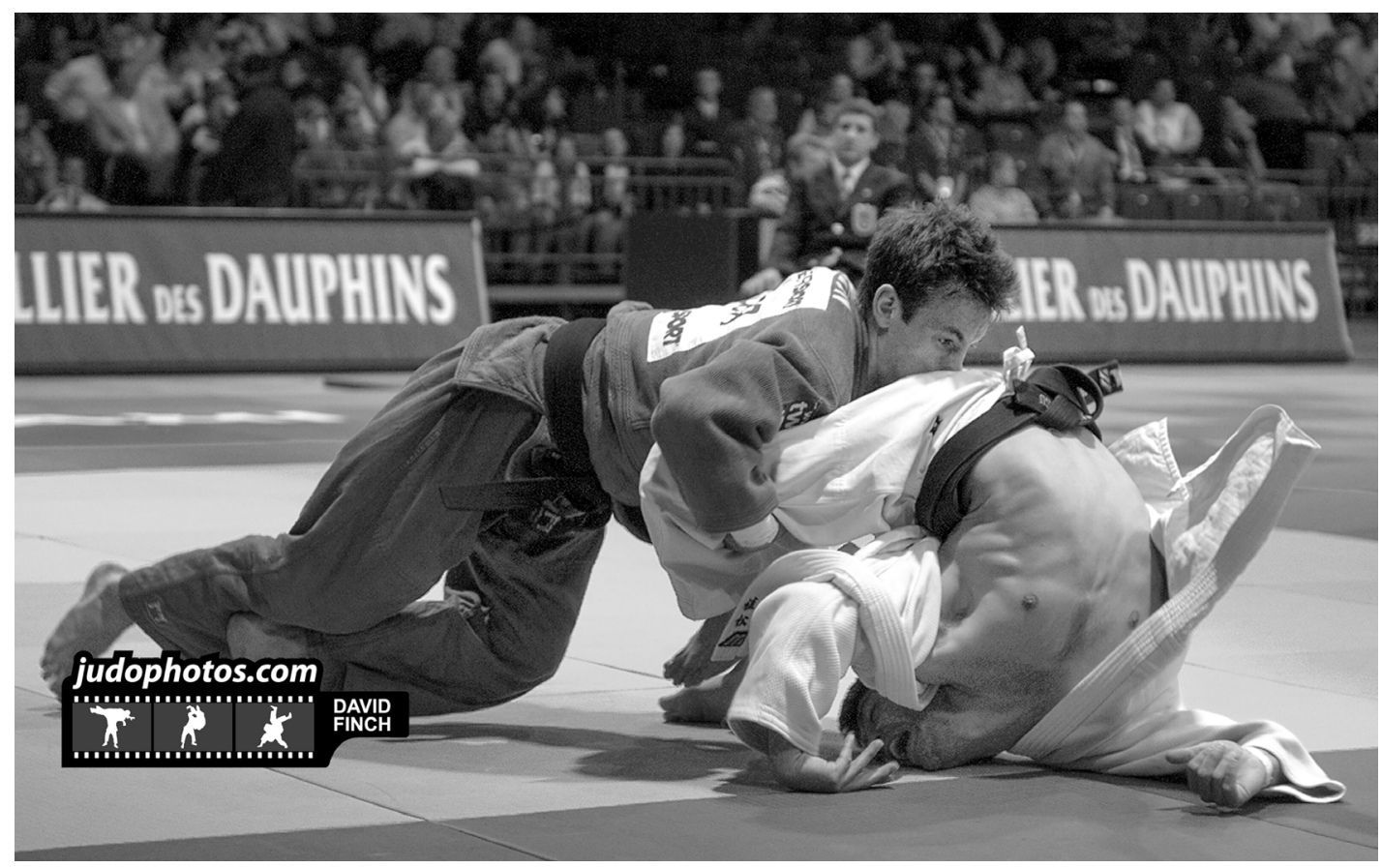

Figure 9: This picture featuring Craig Fallon of Great Britain against Uematsu Kenji of Spain during the 2003 European Championships (-60 kg class) in Düsseldorf, Germany, shows that in elite athletes, dangerous landings and potential ensuing serious injuries are hardly the consequence of one or another technique supposedly being dangerous; rather such injuries are a combination of factors including the deterioration of jūdō techniques into chaotic techniques with loss of balance and control and the opponent's extreme attempts to avoid touching the tatami with a part of the body that would yield a score, in this way leading to unusual attitudes that trade making safe and proper break falls for no score even if that involves serious injury. (Picture reproduced by courtesy of David Finch, Copyright $(\mathbb{C}$ 2003. All rights reserved). 
Citation: De Crée C (2019) Traumatic Atlanto-Axial Rotary Subluxation (AARS) in a 6-Year-Old Child during Recreational Jūdō Practice: A Case Report and Mini-Review of Serious Neck Injuries in Jūdō. Arch Sports Med 3(1):134-148

novice jūdō skills. These techniques typically involve some kind of lever or couple of opposed forces around the opponent's center of mass in order to achieve rotation. Children tend to simply copy what the teacher demonstrates rather than analyzing and understanding the actual mechanism and its essential key points. Although jūdō aims to make use of subtle technique and giving way, such skills are rarely achieved during childhood and at novice level, hence children mostly rely on physical force and interindividual genetic advantages in motor skills. Hence, it is possible for children to introduce errors in techniques that are very rarely or even never seen in adults, even if it were only because of common sense. There is no doubt that the circumstances of the injury here included some extreme technical aberration, such as lifting and attempting to turn the opponent's body while supported only with her head in a flexed or stretched position blocked into mat. We have attempted to recreate the two potential errors in the two most basic turnover techniques, and have juxtaposed the images with the technique being performed correctly (Figure 10 and Figure 11).
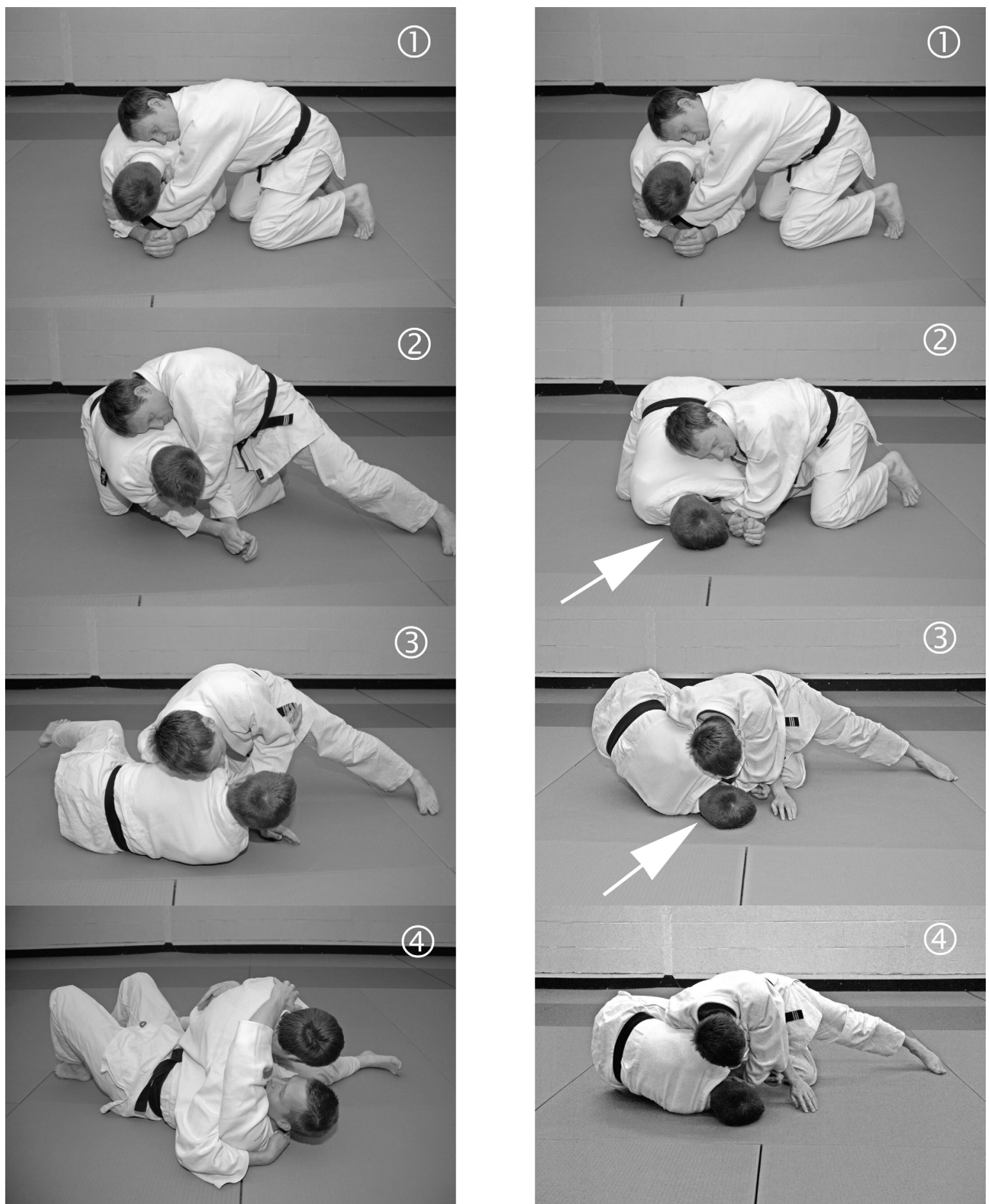

Figure 10: Nogare-kata [turnover exercise] performed on a practice partner seated in yotsunbai [position "on all fours"], i.e. on hands and knees during newaza [mat work] showing the correct (left column) vs. the wrong form (right column). 
Citation: De Crée C (2019) Traumatic Atlanto-Axial Rotary Subluxation (AARS) in a 6-Year-Old Child during Recreational Jūdō Practice: A Case Report and Mini-Review of Serious Neck Injuries in Jūdō. Arch Sports Med 3(1):134-148
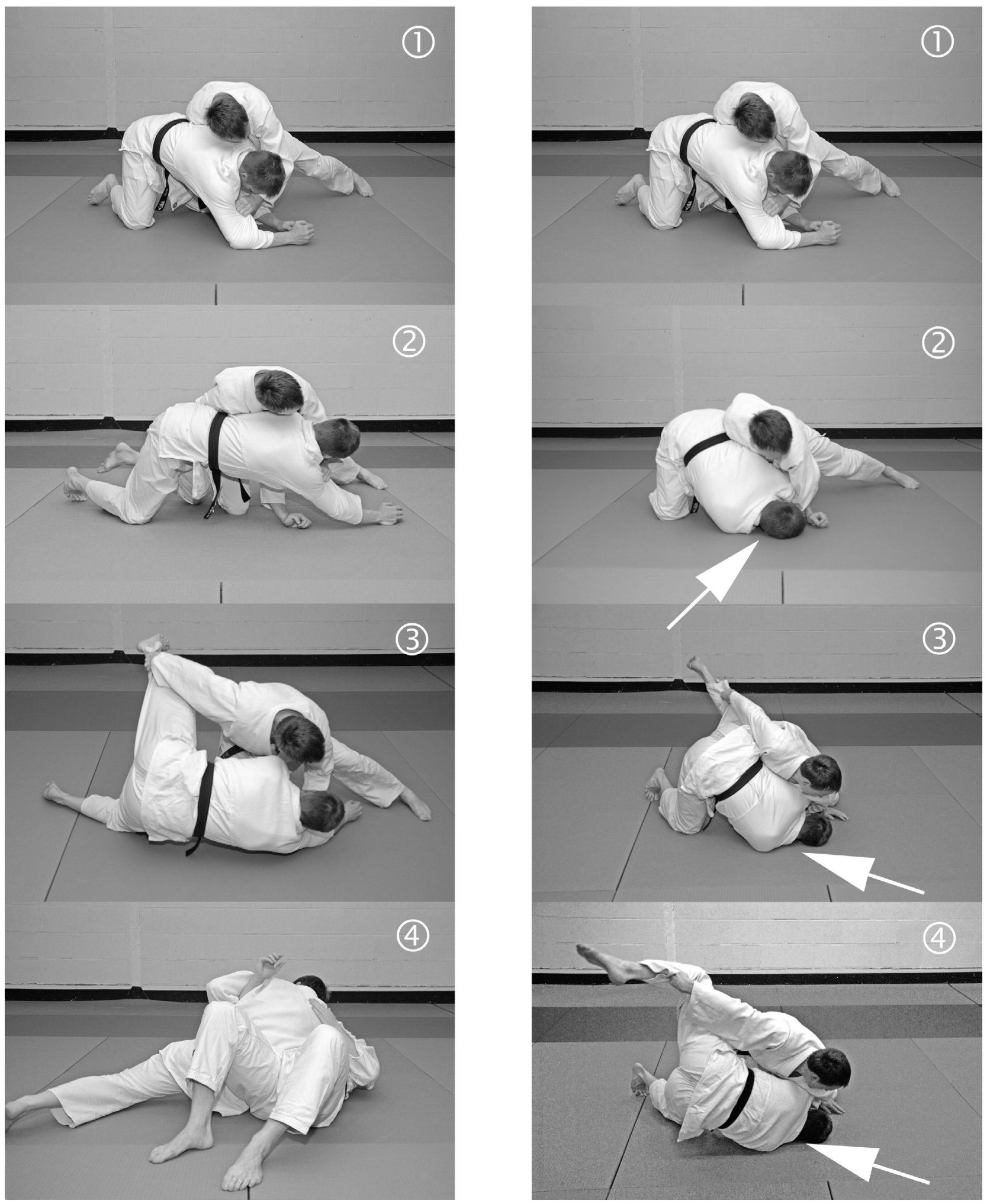

Figure 11: Nogare-kata [turnover exercise] performed on a practice partner seated in yotsunbai [position "on all fours"], i.e. on hands and knees during newaza [mat work] showing the correct (left column) vs. the wrong form (right column).

We note one other case of a serious cervical spinal injury sustained during newaza, and that received extensive media attention. In 2012 Austrian -52 kg jüdōka Jacqueline 'Jacky' Raab (Figure 12), while seated on the jūdō mat in yotsunbai position during newaza received a heavy blow to the back of the neck causing a career-ending C4-C5 cervical vertebral dislocation and $\mathrm{C} 4$ fracture that required surgical fusion. Despite initially being paraplegic she made a full recovery thanks to prompt expert medical attention [40]. 

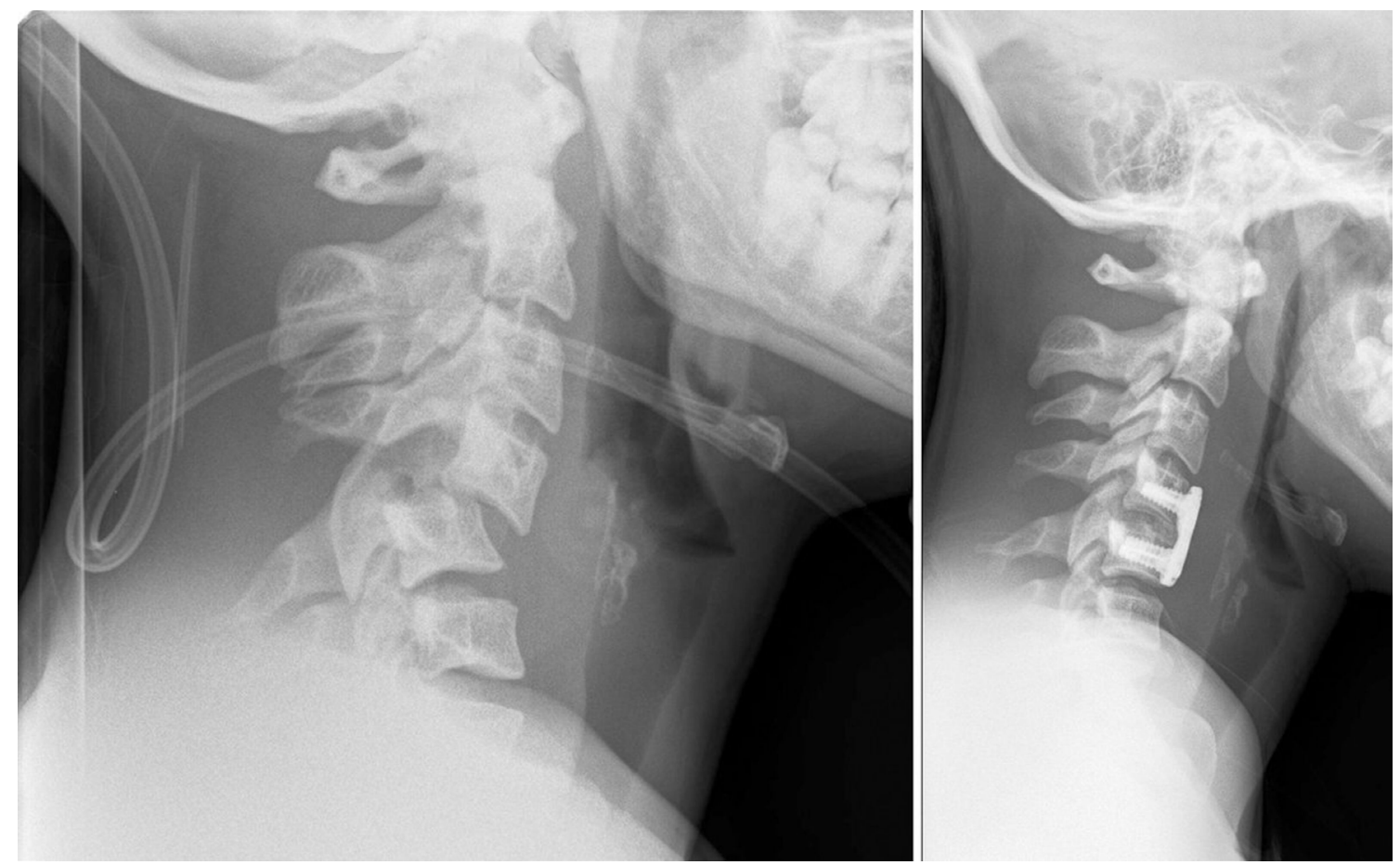

Figure 12: X-ray showing the cervical vertebral dislocation at the C4-C5 level in Austrian - $52 \mathrm{~kg}$ jūdōka Jacqueline 'Jacky' Raab in May 2012, as a result of a heavy blow to the neck during newaza [ground fight or mat work] rather than resulting from a throwing technique.

\section{Injury rate}

Injuries surveys indicate that recreational and competitive practice of $j \bar{u} d \bar{o}$ is associated with a low incidence of neck trauma [8,11,41-43]. Nevertheless, Yard, et al. [9] found higher injury proportion ratios (IPR) of pediatric neck injuries sustained by children practicing jūdō when compared to children practicing karatedō (IPR $=4.73,95 \% \mathrm{Cl}$ : 1.91-11.70) or taekwondō (IPR $=4.17,95 \% \mathrm{Cl}$ : 1.02-17.06). Scarce studies, such as the one by Green, et al. [11], found that neck injuries associated with participation in jūdō contests occurred at a rate of 1.03 per 1000 Athlete Exposures, with one Athlete Exposure representing the susceptibility to injury, expressed as one athlete participating in one match or practice session in which he or she is exposed to the possibility or injury. Recording injuries during adult jūdō world championships Miarka, et al. [44], found $2.9 \%$ of jūdō injuries involving the neck, although further description in their paper suggests that these authors may have used this term rather to indicate normal logical consequences of a successful choke where the opponent did not have a chance or refused to submit, i.e. asphyxiation and/or syncope. According to a 3-year nationwide Japanese survey by Katō, et al. [45], jūdōka accounted for $4.9 \%$ ( $\mathrm{N}=$ 26) of the sports-related spinal injuries, with nearly all of them (>97\%) occurring at the cervical level. The authors did not specify though how many of these involved atlanto-axial subluxations or dislocations with spinal cord injury [45].

Together with closed head trauma, neck injuries rank among the most severe injuries encountered in jūdō. However, from most of these data it is not possible to derive either accurate descriptions of the nature of the neck injuries sustained or estimates of the incidence of AARS (or even cervical spine injuries in general) in either adult or children jūdō practitioners $[9,11,41,43]$. Among 19 severe jūdō cervical spine injuries reported in an 8-year period retrospective study by Kamitami, et al. [6], only a single atlanto-axial subluxation was incurred on a total of 1,572,768 jūdōka. This injury was sustained while being thrown, though a more detailed description of the circumstances was omitted.

\section{Injury risk factors}

Athletes may present with both extrinsic and intrinsic risk factors associated with cervical spinal injuries. Intrinsic factors in sports in general include: eating disorders, loss of body mass [11], menstrual irregularities, osteopenia, gender (women have a higher incidence) [43], leg length discrepancy, insufficient neck muscle strength [38], having a narrow spinal canal [45], low aerobic fitness, and a mismatch between the skills of the athlete and the task attempted [45]. Extrinsic risk factors typically comprise improper footwear, sudden changes in training regimen or surface.

However, it appears that female jūdō athletes sustain higher general injury rates than males [42], and also are more predisposed to injuries during newaza in comparison to males [44]. The gender effect is outspokenly clear for certain injuries in jūdō including cervical neck injuries [43], and this despite the fact that male jūdōka generate considerably more power in throwing than female jūdōka, due to their higher muscular force and body mass, and because, historically, they more often choose techniques where the opponent is thrown from increased height (e.g.: ura-nage [reverse throw], kata-guruma [shoulder wheel], daki-wakare [high-lift and-separating throw], te-guruma [hand wheel], morote-gari [double-leg-reaping throw]). 
Citation: De Crée C (2019) Traumatic Atlanto-Axial Rotary Subluxation (AARS) in a 6-Year-Old Child during Recreational Jūdō Practice: A Case Report and Mini-Review of Serious Neck Injuries in Jūdō. Arch Sports Med 3(1):134-148

Most cervical neck injuries in jūdō, including the one we introduced in this case study, involve younger and less experienced jūdōka [9]. Likely, one of the reasons that such injuries are far less frequent in elite athletes - even when chaotic techniques are involved - is the ability, which comes with advanced skills and talent, i.e., to safely recover from unusual attitude upsets or from a movement that involves loss of control and that goes awry. Mastership of ukemi break falls is essential to avoid injury when undergoing a jūdō throwing technique. During novice training practice this requires that the tori [the one performing the technique] holds on to the arm of the uke [his or her training partner who is undergoing the technique] in this way facilitating the uke's break fall action. During contests various alterative gripping strategies are employed that may require higher breakfalling skills [46].

Although the risk of neck or head injury during poorly executed throws is commonly appreciated among jūdō coaches and researchers, the same injuries resulting from newaza or groundwork actions appear to be largely underappreciated. Yet, circumstances during which the atlanto-axial subluxation in the 6-year-old child occurred, did not involve any throwing, and neither did the one involving former Austrian champion Jacqueline Raab [40]. Both injuries occurred during newaza.

That the three afore-mentioned cases of elite jūdōka involved females, just as the case we are introducing in this paper, may well not be a coincidence. In most cases, where male elite athletes hit the tatami in a very unfortunate position (see Figure 9) they mostly seem to recover fairly quickly with no serious injury, or only musculo-tendinous elongations or minor ruptures but no dislocations or fractures. This gender difference is not difficult to understand. Male elite jūdōka typically engage in extensive weight-bearing training making their bones very strong. Women elite jūdōka also engage in weight training and weight-bearing exercices but less excessively; moreover, they often wrestle with eating disorders and severe dietary issues in trying to stay in their weight class, which often results in menstrual problems and hypoestrogenemia causing a weakening of their bone mineral structure [47]. Their musculature supporting their bones generally is also less excessively developed than in male elite jūdō athletes due to basic gender anthropometric differences. Previous surveys such as the one by Green, et al. [11], have shown that adult female jūdōka sustain significantly more injuries during newaza [groundwork], than males do. To the best of our knowledge sufficient data are not available on the gender difference in injuries in juvenile jūdōka. However, Yard, et al. [9] proposed that the reason for the unexpectedly high jūdō injury rate among young girls was probably that as a minority group in many clubs they often had to train with boys and men. In our opinion, this speculation lacks solid evidence, and injury rates during contests of juveniles are often also higher among girls, and these contests are not mixed.

A number of authors, such as, for example, Kamitami, et al. [6] rather unconvincingly have previously attempted to connect specific jūdō throws to neck injuries (notably, ō-sotogari [major outer reaping throw], suwari-seoi-nage [kneeseated shoulder throw], and uchi-mata [inner thigh throw]), even going as far as characterizing them as dangerously though lacking any direct proof. Especially much has been speculated about suwari-seoi-nage (erroneously referred to as "drop seoi-nage" in North-America and some Englishspeaking countries), a throw where the throwing athlete takes a very low position on both knees sometimes leaving barely any space for his opponent to be properly turned on his back while being thrown over the shoulder, and in worst case scenarios, on the head or forehead. This is, however, a matter of poor execution of the technique, as when properly performed the scenario going awry is nearly impossible due to continued rotation of the thrower hence allowing his opponent to perfectly break fall.

If any of the aforementioned standard jūdō throws really would be inherently dangerous it is then remarkable that throws such as $\bar{o}$-soto-guruma [major outer wheel] or ura-nage [reverse throw], both generally considered as particularly high-impact throws are completely absent from lists of suspects. Whilst one would indeed expect these throws to be rare among novice jūdōka they are observed at a regular frequency in elite level tournaments. Ishikawa, et al. [48], demonstrated that any assertion that any of these throws would be so dangerous and would be causing head or neck injuries is without merit. It is true that the maximal rotational acceleration of the uke's head was greater when being thrown with $\bar{o}$-soto-gari [major outer reaping throw] $\left(603.2 \mathrm{rad} / \mathrm{s}^{2}\right)$ than with several other throws (o-uchigari [major inner reaping throw] [401.6 rad $/ \mathrm{s}^{2}$ ], seoi-nage [shoulder-back-carrying throw] [276.2 rad/ $/ \mathrm{s}^{2}$ ], and tai-otoshi [body drop] [368.3 rad/s $/ \mathrm{s}^{2}$ ]). However, $4.500 \mathrm{rad} / \mathrm{s}^{2}$ rotational acceleration is estimated as necessary to cause concussion among those adults most prone to concussions [49]. Rather than any of these jūdō throws in themselves being dangerous we believe that it is the mismatch between the skills of the athlete and the task attempted that significantly contributes to the injury risk.

Whilst the effect of different types of tatami on kinetic variables has been extensively studied, experimental data on the relationship between jūdō injuries and different floor systems are lacking. It is nevertheless likely that cervical injuries during tachi-waza [standing] jūdō could be limited if only proper floor systems were in use. Repetitively falling as a result of jūdō throws produces considerable stress on the spine. Jūdō, typically, is a very low-budget sport. This, together with the absence of technical know-how and traditional culture, implies that the laborious construction concept and costs involved in properly building proper floating floor systems is not an option for the majority of jūdō clubs located outside Japan. Oftentimes polyurethane tatami [Japanese jūdō practice mats] of approximately $4 \mathrm{~cm}$ thickness are positioned straight on a concrete underground instead of on a dedicated steel coil spring-supported floating wooden floor as was originally intended. Consequently, recreational and competitive jūdō activity in the West tends to take place on improper jūdō floor systems. Even if proper floor systems might help reducing cervical injuries in standing $j u \bar{d} \bar{o}$, it is unlikely that a floating floor would exert much effect on limiting cervical injuries incurred during newaza 
Citation: De Crée C (2019) Traumatic Atlanto-Axial Rotary Subluxation (AARS) in a 6-Year-Old Child during Recreational Jūdō Practice: A Case Report and Mini-Review of Serious Neck Injuries in Jūdō. Arch Sports Med 3(1):134-148

[groundwork] because of the different mechanisms involved.

It also must be pointed out that in Shōrinji kenpō [Shaolin Temple boxing], and several in koryū bujutsu [Japanese traditional martial arts schools] such as Kitō-ryū, Takenouchiryū, and Yagyū shingan-ryū, practitioners make no use of tatami mats, but tend to throw their training partners directly onto uncovered wooden floors, and they do so without significant injury rates. Proper mastery of breakfall techniques, no doubt, is key to achieving this.

Catanese [36] speculated that there is probably a relationship between cervical injuries and muscle weakness, and suggested that jūdō athletes should not participate in tournaments until they have developed sufficient muscular strength in their necks. However, as solid evidence is still lacking that neck muscle strength can prevent such injuries in $j u \bar{d} \bar{o}$, we would at least encourage instructors to put increased efforts in teaching and emphasizing the importance of proper control during jū $\bar{d} \bar{o}$ training practice when executing any jū $\bar{d} \bar{o}$ movement, whether it involves throwing during standing $j \bar{u} d \bar{o}$ or turnovers or other techniques during ground work. Coordinative capability, static-dynamic balance capability, and timing capability are motor control aspects that require time and far exceed simply mimicking the movements of a jūdō throw. This is an important concern when teaching jūdō. While we do not believe that any of the throws mentioned are dangerous, it is debatable whether the curricular position of all jūdō techniques is optimal, especially when considering children.

\section{Recommended treatment}

Treatment options are affected by both the severity and the duration of symptoms. The vast majority can be managed with non-operative treatment by observation or traction $[13,14,27,30,50-54]$. Light cases with symptoms lasting less than one week of duration may adequately respond to combined benzodiazepines and non-steroidal antiinflammatory drugs (NSAIDS), soft collar, and stretching and muscle strengthening exercise therapy. In case symptoms and persistent subluxation have been present for a duration of between 1 week to 1 month, analgesics and muscle relaxants likely will have to be accompanied by halter-traction therapy either at home or in a hospital setting, followed by 4 to 6 weeks of wearing a soft collar for post-reduction immobilization purposes. Any nonresponding cases or when subluxation and symptoms have been present for more than a month, closed reduction using 3 weeks of halo-traction with gradually increasing weights, followed by 6 weeks of halovest immobilization will be necessary $[13,14,55]$.

If previous attempts fail, or when the patient shows neurological deficits or subluxation is recurrent, unstable or has been present for 3 months or longer, successful closed reduction by halo-traction may no longer be an option, and C1-C2 open reduction, posterior spinal instrumentation and permanent arthrodesis (fusion in situ) using C1 lateral mass and C2 pars screws or using C1-C2 transarticular screws and/or sublaminar wiring, supplemented by halo vest immobilization, will be the only remaining solution and treatment of choice [56]. In that case, neck limited range of motion will be permanent.

Cervical injuries in children require even more special attention and care $[27,30,50-54]$. Because of a substantial risk for the injury to reoccur or become unstable this time perhaps with neurological consequences, even after recovery contact sports may not be recommended in pediatric patients at least until postpuberty when musculature and skeletal maturity will offer better protection. Although no longitudinal studies on AARS in jūdōka exist, combat sports including jūdō practice are likely particularly unsuited after such injury, especially in children, unless one engages only in carefully selected exercises and refrains from falling and randori (free combat exercise). If a person insists on returning to jūdō one day, it is likely prudent to wait until the person has obtained adult stature and body mass, and can engage in serious strength and conditioning training with specific attention for neck musculature.

\section{Uniqueness of the study}

Pediatric acute atlanto-axial rotational subluxations have not been previously described in association with jūdō, which as a combat sport creates specific etiological circumstances and predisposing factors.

\section{Conclusions}

In jūdō most serious neck injuries occur at the C4-C5 level, with prepubertal girls and young women appearing to be most at risk. The mechanism most frequently involved in severe neck injuries whether incurred during tachi- or in newaza is not fundamentally different, i.e.: a hyperflexed or -stretched neck getting blocked between the victim's shoulder and tatami with the opponent pushing down on and attempting to rotate the victim's body while ignoring the dangers of their trapped head. A mismatch between the skills of the athlete and the task attempted, contributes to the injury risk. Among neck injuries associated with jūdō practice traumatic acute atlanto-axial rotational subluxation should be considered as a potential diagnosis, especially in jūdōka presenting with torticollis following mechanical impact or a movement that involved severe pressure on their head when trapped in a tilted position. Prompt and correct diagnosis is crucial, preferably by open-mouth X-rays, and by $\mathrm{CT}$ scan and $\mathrm{MRI}$, to ensure proper management and prevent neurological complications. There are insufficient data available to properly underpin standards of prognosis for further recreational jūdō practice or competition, as most subjects who have incurred such injuries seem to have retired from and never returned to jūdō. Likely, prepubertal children should not return to jūdō practice until skeletal maturity, at least, although isolated cases exist of female adult elite jūdō athletes with serious neck injuries who successfully returned to international competitive jūdō.

\section{Learning Points/Take-home Messages}

- Always suspect atlantoaxial subluxation in cases of torticollis.

- Thin-section multidetector CT scan with sagital and coronal reformats is the gold standard in investigation. 
Citation: De Crée C (2019) Traumatic Atlanto-Axial Rotary Subluxation (AARS) in a 6-Year-Old Child during Recreational Jūdō Practice: A Case Report and Mini-Review of Serious Neck Injuries in Jūdō. Arch Sports Med 3(1):134-148

- Treatment in most of the cases is non-operative using non-steroidal anti-inflammatory drugs, soft collar and sedation if needed.

- Cases with delayed diagnosis and treatment are more likely to need operative interventions and may suffer from serious neurological complications.

\section{Acknowledgements}

We thank our colleagues Anton Veyt, MD, Department of Neurosurgery, Academic Hospital Sint-Maarten, Mechelen, and Pierre Moens, MD, and Sebastiaan Schelfaut, MD, both of the Department of Orthopedics of the University Hospital Leuven Campus Pellenberg. Ir. Stijn Coertjens, PhD, jūdō black belt $3^{\text {rd }}$ dan, and Tim Spellemans, MA, jūdō $3^{\text {rd }}$ dan, both of the Royal Jūdō \& Karate Academy Bushidō-Kwai Mechelen, stood as models for the jūdō turnover techniques demonstrated in Figures 10 and Figure 11. Line drawings and art illustrations were kindly created by Marit Delplace.

\section{References}

1. (2012) Three high school students died in school judo activities in 2011.

2. Harmer PA (2009) Judo. Chapter 13. In: Caine DJ, Harmer PA, Schiff MA, Epidemiology of Injury in Olympic Sports. WileyBlackwell, Oxford, UK, 165-166.

3. Uchida R (2011) Deaths during the judo classes and activities conducted under the supervision of schools in Japan; From 1983 to 2009 All cases listed and analyzed. Aichi University of Education.

4. Burke M (2010) 108 School judo class deaths but no charges, only silence. The Japan Times.

5. Kamitani T, Malliaropoulos NG, Omiya M, et al. (2017) On the way to the Tokyo Summer Olympic Games (2020). Prevention of severe head and neck injuries in judo: It's time for action. $\mathrm{Br} J$ Sports Med 51: 1581-1582.

6. Kamitani T, Nimura Y, Nagahiro S, et al. (2013) Catastrophic head and neck injuries in judo players in Japan from 2003 to 2010. Am J Sports Med 41: 1915-1921.

7. Mutō Y, Yamashita T, Tanaka Y (2016) Budō no spōtsu igaku [Martial arts sports medicine]. Bēsubōru Magazin-sha [Baseball Magazine company], Tōkyō, 1-191.

8. Pocecco E, Ruedl G, Stankovic N, et al. (2013) Injuries in judo: A systematic literature review including suggestions for prevention. Br J Sports Med 47: 1139-1143.

9. Yard EE, Knox CL, Smith GA, et al. (2007) Pediatric martial arts injuries presenting to Emergency Departments, United States 1990-2003. J Sci Med Sport 10: 219-226.

10. Zetaruk MN (2014) Spinal injuries in combat Sports. Chapter 11. In: Micheli L, Stein C, O'Brien M, et al. Spinal Injuries and Conditions in Young Athletes. Springer, New York, 105-114.

11. Green CM, Petrou MJ, Fogarty-Hover ML, et al. (2007) Injuries among judokas during competition. Scand J Med Sci Sports 17: 205-210.

12. Bagouri E, Deshmukh S, Lakshmanan P (2014) Atlantoaxial rotatory subluxation as a cause of torticollis in a 5-year-old girl. BMJ Case Rep.
13. Labler L, Eid K, Platz A, et al. (2004) Atlanto-occipital dislocation: Four case reports of survival in adults and review of the literature. Eur Spine J 13: 172-180.

14. Mueller FJ, Kinner B, Rosskopf M, et al. (2013) Incidence and outcome of atlanto-occipital dissociation at a level 1 trauma centre: A prospective study of five cases within 5 years. Eur Spine J 22: 65-71.

15. Freeman BJ, Bisbinas I, Nelson W (1998) Traumatic atlantoaxial subluxation and missed cervical spine injuries. Hosp Med 59: 330-331.

16. Hicazi A, Acaroglu E, Alanay A, et al. (2002) Atlantoaxial rotatory fixation-subluxation revisited: A computed tomographic analysis of acute torticollis in pediatric patients. Spine (Phila Pa 1976) 27: 2771-2775.

17. Mönckeberg JE, Tomé CV, Matías A, et al. (2009) CT scan study of atlantoaxial rotatory mobility in asymptomatic adult subjects: A basis for better understanding C1-C2 rotatory fixation and subluxation. Spine (Phila Pa 1976) 34: 1292-1295.

18. Sobolewski BA, Mittiga MR, Reed JL (2008) Atlantoaxial rotary subluxation after minor trauma. Pediatr Emerg Care 24: 852-856.

19. Van Alff R (1996) Jūdō-100 turnovers: Dynamics in grappling techniques. The Nether-lands, 126-127.

20. Ishii K, Chiba K, Maruiwa H, et al. (2006) Pathog-nomonic radiological signs for predicting prognosis in patients with chronic atlantoaxial rotatory fixation. J Neurosurg Spine 5: 385391.

21. Fielding JW, Hawkins RJ (1977) Atlanto-axial rotatory fixation. (Fixed rotatory subluxation of the atlanto-axial joint). J Bone Joint Surg Am 59: 37-44.

22. Menezes AH, Traynelis VC (2008) Anatomy and biomechanics of normal craniovertebral junction (a) and biomechanics of stabilization (b). Child's Nervous System 24: 1091-1100.

23. Riascos R, Bonfante E, Cotes C, et al. (2015) Imaging of atlantooccipital and atlantoaxial traumatic injuries: What the radiologist needs to know. Radiographics 35: 2121-2134.

24. Nannapaneni R, Nath FP, Papastefanou SL (2001) Fracture of the clavicle associated with a rotatory atlantoaxial subluxation. Injury 32: 71-73.

25. de Kroon K, Den Boer W, Halbertsma FJ (2010) A child with a abnormal neck posture after doing a head-over-heels. Eur J Pediatr 169: 1279-1281.

26. Bogduk N, Mercer S (2000) Biomechanics of the cervical spine. I: Normal kinematics. Clin Biomech (Bristol, Avon) 15: 633-648.

27. Steinmetz MP, Lechner RM, Anderson JS (2003) Atlantooccipital dislocation in children: Presentation, diagnosis, and management. Neurosurg Focus.

28. Holmes JF, Akkinepalli R (2005) Computed tomography versus plain radiography to screen for cervical spine injury: A metaanalysis. J Trauma 58: 902-905.

29. Montgomery JL, Montgomery ML (1994) Radiographic evaluation of cervical spine trauma. Procedures to avoid catastrophe. Postgrad Med 95: 173-174.

30. Rojas CA, Hayes A, Bertozzi JC, et al. (2009) Evaluation of the C1C2 articulation on MDCT in healthy children and young adults. AJR Am J Roentgenol 193: 1388-1392.

31. (2016) Craniovertebral Junction Trauma. Obgyn Key. 
Citation: De Crée C (2019) Traumatic Atlanto-Axial Rotary Subluxation (AARS) in a 6-Year-Old Child during Recreational Jūdō Practice: A Case Report and Mini-Review of Serious Neck Injuries in Jūdō. Arch Sports Med 3(1):134-148

32. Aultman CD, Drake JD, Callaghan JP, et al. (2004) The effect of static torsion on the compressive strength of the spine: An in vitro analysis using a porcine spine model. Spine (Phila Pa 1976) 29: E304-E309.

33. Drake JD, Aultman CD, McGill SM, et al. (2005) The influence of static axial torque in combined loading on intervertebral joint failure mechanics using a porcine model. Clin Biomech (Bristol, Avon) 20: 1038-1045.

34. Dvorak J, Schneider E, Saldinger P, et al. (1988) Biomechanics of the craniocervical region: The alar and transverse ligaments. J Orthop Res 6: 452-461.

35. Robinson Y, Kayser R, Ertel W, et al. (2007) Traumatic cervical instability in martial arts. Scand J Med Sci Sports 17: 92-93.

36. Catanese AJ (2012) The medical care of the judoka: A guide for athletes, coaches and referees to common medical problems in judo. Wheatmark, Inc, Tucson, 118-121.

37. Vandecaveye G (2013) Gella Vandecaveye: Vertebral neck fracture. European Women's Team Championships, Villach, Austria.

38. Uzel A-P, Massicot R, Delattre O, et al. (2005) Fracture-luxation uni-articulaire C5-C6 lors d'une compétition de judo: L'uchi-mata en cause Unilateral $\mathrm{C} 5 \mathrm{C} 6$ facet fracture dislocation caused by an uchi-mata (judo inner thigh throw). Journal de Traumatologie du Sport 22: 65-69.

39. BK (2018) Le directeur technique national parle des derniers instants de Fanta Keïta. Senegal, Dakar.

40. Wings for Life World Run (2018) Jacky Raab: “My stroke of luck shouldn't be a one-off!". Fuschl am See, Austria: Red Bul GmbH.

41. Akoto R, Lambert C, Balke M, et al. (2018) Epidemiology of injuries in judo: A cross-sectional survey of severe injuries based on time loss and reduction in sporting level. Br J Sports Med 52: 1109-1115.

42. James G, Pieter W (2003) Injury rates in adult elite judoka. Biology of Sport 20: 25-32.

43. Kujala UM, Taimela S, Antti-Poika I, et al. (1995) Acute injuries in soccer, ice hockey, volleyball, basketball, judo, and karate: Analysis of national registry data. BMJ 311: 1465-1468.
44. Miarka B, Dal Bello F, José Brito C, et al. (2018) Injuries during a world judo championship: Differences between sex, weight category and competition phase. Int J Perform Anal Sport 19: 229-244.

45. Katō S, Shingu H, Ikata T, et al. (1996) Sports-related spinal cord injury in Japan (from the nationwide spinal cord injury registry between 1990 and 1992). Spinal Cord 34: 416-421.

46. van Swigchem R, Groen BE, Weerdesteyn V, et al. (2009) The effects of time pressure and experience on the performance of fall techniques during a fall. J Electromyogr Kinesiol 19: 521-531.

47. Nader S (1996) Female judoists: Their hormones, muscles, and bones. Lancet 347: 919-920.

48. Ishikawa Y, Anata K, Hayashi H, et al. (2018) Effects of different throwing techniques in judo on rotational acceleration of uke's head. Int J Sport Health Sci 16: 173-179.

49. Ommaya AK (1984) Biomechanics of Head Injuries: Experimental aspects, biomechanics of trauma. In: Nahum A, Melvin JW, Appleton-Century-Crofts, East Norwalk, CT.

50. Bulas DI, Fitz CR, Johnson DL (1993) Traumatic atlanto-occipital dislocation in children. Radiology 188: 155-158.

51. Kaufman RA, Dunbar JS, Botsford JA, et al. (1982) Traumatic longitudinal atlanto-occipital distraction injuries in children. AJNR Am J Neuroradiol 3: 415-419.

52. Lee SC1, Lui TN, Lee ST (2002) Atlantoaxial rotatory subluxation in skeletally immature patients. Br J Neurosurg 16: 154-157.

53. Münch C, Linhart W, Storck A, et al. (2005) Treatment of traumatic rotatory atlanto-axial subluxation in childhood. Case report and literature review. Unfallchirurg 108: 987-990.

54. Warner WC, Hedequist DJ (2015) Cervical Spine injuries in Children. In: Beaty J, Kasser J, Fractures in Children. ( $7^{\text {th }}$ edn), Lippincott Williams \& Wilkins, Philadelphia, PA, 1: 845-898.

55. Chechik O, Wientroub S, Danino B, et al. (2013) Successful conservative treatment for neglected rotatory atlantoaxial dislocation. J Pediatr Orthop 33: 389-392.

56. Hedequist D, Hresko T, Proctor M (2008) Modern cervical spine instrumentation in children. Spine (Phila Pa 1976) 33: 379-383.

DOI: $10.36959 / 987 / 241$

Copyright: (C) 2019 De Crée C. This is an open-access article distributed under the terms of the Creative Commons Attribution License, which permits unrestricted use, distribution, and reproduction in any medium, provided the original author and source are credited. 